\title{
O uso de câmeras e microfones escondidos e a adoção de falsa identidade no jornalismo investigativo: necessário ou anti-ético ? ${ }^{1}$
}

Júlia Almeida

Pontifícia Universidade Católica do Rio de Janeiro - PUC-Rio

Departamento de Comunicação Social - Bacharelado em Jornalismo

\section{RESUMO}

O objetivo deste artigo é contribuir para o debate sobre até que ponto é ético o uso de tecnologia (câmeras e/ou gravadores) escondida e de uma falsa identidade por parte do repórter em reportagens investigativas. Para isso, é necessário, primeiramente, refletir sobre a relevância do jornalismo investigativo para a sociedade, analisando suas origens e identificando o momento em que começou a ocorrer as práticas do uso de tecnologia e de falsa identidade para obter informações. O tema é analisado por meio do estudo das reportagens investigativas "Corrupção em São Gonçalo", "Queima de documentos da ditadura" e "Roubo de celulares" do programa Fantástico, da Rede Globo. Nelas, podemos ver os desdobramentos e as consequências de reportagens que se utilizaram das tecnologias para fazer denúncias e causaram grande repercussão no público.

\section{PALAVRAS-CHAVE}

Jornalismo investigativo; Câmera escondida; Ética; Programa Fantástico; Telejornalismo.

\section{Introdução}

O objetivo deste artigo é contribuir para o debate sobre até que ponto é ético o uso de tecnologia (câmeras e/ou gravadores) escondida e de uma falsa identidade por parte do repórter em reportagens investigativas. Para isso, é necessário, primeiramente, refletir sobre a relevância do jornalismo investigativo para a sociedade, analisando suas origens e identificando o momento em que começou a ocorrer as práticas do uso de tecnologia e de falsa identidade para obter informações.

\footnotetext{
${ }^{1}$ Artigo derivado de monografia de graduação em Jornalismo, orientada pela professora Lilian Saback e apresentada em dezembro de 2019.
} 
É também pertinente pensar sobre as transformações que ocorreram no jornalismo investigativo como consequência do surgimento e desenvolvimento das novas tecnologias que passaram a ser utilizadas. Para isso, torna-se necessário debater o papel deste jornalismo como meio de esclarecer assuntos de interesse público e diferenciar os limites que ele teoricamente deveria seguir e o que na prática acaba seguindo. Por fim, é relevante também avaliar a figura do repórter que adota diferentes "profissões e personalidades" com a finalidade de obter informações que não conseguiria caso se apresentasse como um jornalista.

O tema é analisado por meio do estudo das reportagens investigativas "Corrupção em São Gonçalo"2, "Queima de documentos da ditadura"3 e "Roubo de celulares"4 do programa Fantástico, da Rede Globo. As três, que são de épocas distintas, envolvem o uso da câmera oculta e da falsa identidade com o objetivo de conseguir informações que não seriam conseguidas caso o repórter se apresentasse como jornalista. Nelas, podemos ver os desdobramentos e as consequências de reportagens que se utilizaram das tecnologias para fazer denúncias e causaram grande repercussão no público.

O estudo de caso como metodologia ajuda a "ilustrar determinados tópicos dentro de uma avaliação, às vezes de modos descritivo ou mesmo de uma perspectiva jornalística" (DUARTE, 2009, p.220). O estudo de caso das reportagens aqui analisadas é feito a partir dos conceitos chaves de "jornalismo investigativo", "ética" e "interesse público", que são de compreensão fundamental na discussão do tema. O conceito de Jornalismo Investigativo parte da definição do jornalista Leandro Fortes, que o qualifica como "reportagens de mais fôlego, de maior investimento de apuração. Aquela que exige mais tempo e paciência de pesquisas, entrevistados, observação direta, checagem e rechecagem - a busca obsessiva por documentos e provas" (2005, p.22). Ou seja, as matérias consideradas investigativas seriam diferentes das que aparecem em noticiários do dia a dia pois seriam mais trabalhosas e exigiriam do repórter maior dedicação, esforço e tempo.

\footnotetext{
${ }^{2}$ http://memoriaglobo.globo.com/programas/jornalismo/programas-jornalisticos/fantastico/o-reporter-semrosto.htm.

3 http://memoriaglobo.globo.com/programas/jornalismo/telejornais-e-programas/fantastico/fantastico-queima-dedocumentos-da-ditadura.htm.

${ }^{4}$ http://g1.globo.com/fantastico/noticia/2018/01/com-aplicativo-espiao-instalado-siga-caminho-que-celularroubado-percorre.html.
} 
Segundo Saback, é essencial tentar esclarecer as diferenças entre os conceitos de interesse público e interesse do público (2018, p.291). Para tal, será utilizada a concepção elaborada pelo pesquisador luso-brasileiro Carlos Chaparro, que define o interesse do público como algo que pertence "ao universo dos indivíduos, em configurações individuais ou coletivas. Está, portanto, relacionado às razões emocionais e/ou objetivas das pessoas" (2011, p.8). Já o interesse do público, para o autor, seria os bens imateriais e os valores concretos que pertencem a todos.

Já o conceito de ética no jornalismo, para Saback, apesar de ser tratada como algo abstrato, que estaria apenas na esfera da nossa subjetividade e não dos nossos atos objetivos, ela se encontraria no centro do debate sobre as práticas jornalísticas. Para definição de tal conceito, será utilizado o jornalista Eugenio Bucci, que afirma que "cada um, agindo eticamente constrói o próprio caráter em direção à virtude; no mesmo movimento, constrói o bem comum tal como ele é entendido em sua comunidade" (2000, p.16). O autor ainda tem como mantra a máxima de Claudio Abramo, que afirma que "minha ética como marceneiro é igual à minha ética como jornalista - não tenho duas" (ABRAMO, 1997, p.109).

Ao longo de sua história, o jornalismo sofreu diversos e constantes processos de adaptações aos diversos meios. Atualmente vivemos na era da tecnologia, e com as transformações do mercado e da incorporação da tecnologia no exercício do jornalismo, o gênero investigativo vem demarcando mais seu espaço e expertise (PANACIONI, 2015, p.10). O desenvolvimento tecnológico ocorrido nas últimas décadas possibilitou a junção do uso de tecnologias, como câmeras e microfones, aos disfarces. O propósito alegado pelos jornalistas que o utilizam esses recursos é de revelar o que, de outra forma, continuaria supostamente escondido.

Em muitos casos, os jornalistas investigativos são questionados sobre a legalidade e a ética dos métodos utilizados, o que fomenta polêmicas, debates e dúvidas. Apesar de o Código de Ética dos Jornalistas assegurar o direito ao profissional de divulgar qualquer informação que seja de interesse público ${ }^{5} 4$, há um conflito em relação à divulgação do rosto de qualquer pessoa envolvida na investigação. Torna-se, portanto, importante discutir e analisar os limites dessa profissão. Embora envolva uma questão ética fundamental, porque implica a discussão

${ }^{5}$ OMBUDSMAN. Código de Ética dos Jornalistas Brasileiros. O Povo. Disponível em: https://www20.opovo.com.br/app/ombudsman/2012/02/07/notombudsman,2779908/codigo-de-etica-dosjornalistas-brasileiros.shtml. Consultado em 01 de maio de 2019. 
dos limites e procedimentos adequados para a prática jornalística, o tema do repórter infiltrado não tem recebido a devida atenção de pesquisadores brasileiros (MORETZSOHN, 2013, p.90). Menos ainda dos profissionais da área, que costumam manifestar-se apenas quando algum colega se torna vítima em sua empreitada, como ocorreu com Tim Lopes, assassinado em 2002 por traficantes da Vila Cruzeiro, favela do Complexo do Alemão. Segundo a autora, ocasiões assim demonstram a urgência desse tipo de debate que acaba sempre por ser adiado. "Definir limites à atividade jornalística seria uma inaceitável e odiosa restrição à liberdade de informação, cuja principal vítima seria o próprio público" (MORETZSOHN, 2013, p. 101).

\section{Jornalismo, uma profissão em mutação}

O jornalismo nunca foi uma profissão imutável. E nem poderia, levando em conta seu objetivos e propósitos. Ao longo das décadas, o ofício de jornalista foi mudando e se adaptando as constantes transformações decorrentes do surgimento de novas ferramentas e de novas tecnologias. Cada vez mais, e mais rapidamente, vemos mudanças nas práticas de apuração e construção de notícias. Segundo, Nelson Werneck Sodré (1966), desde o início do século $X X$, várias inovações e equipamentos como o telefone, o telégrafo e a máquina de escrever, permitiram que a informação transitasse em maior velocidade, o que resultou em mudanças no modo de fazer o jornalismo. Esses dispositivos tornaram-se ferramentas que contribuíram de forma significativa e indispensável para a evolução da técnica e da prática da profissão.

Os aspectos tecnológicos condicionaram o ritmo e a velocidade da produção em diferentes épocas do desenvolvimento do jornalismo. Este condicionamento não se resume a uma ideia contemporânea de produtividade e eficiência, mas se refere principalmente às possibilidades que os incipientes recursos técnicos estabeleciam para que a produção pudesse mesmo cumprir suas etapas, sua regularidade de circulação e sua busca de garantir o caráter recente das notícias. (FRANCISCATO, 2005, p.48)

Segundo Lopes, o final do século $X X$ até o momento atual é marcado pela evolução nos processos comunicacionais da sociedade, que impactam diretamente o profissional do jornalismo. As diversas mudanças mudaram os princípios básicos na execução do jornalismo e surge, então, uma necessidade de se adequar a uma rotina, em um modelo organizativo da 
empresa noticiosa, agora para o ambiente digital (LOPES, 2019, p.2). Com a internet, microfones e câmeras, um novo leque de possibilidades foi aberto para novos métodos de apuração, sobretudo no jornalismo investigativo. Foi possível, então, deixar registrado em vídeo e áudio para que todos pudessem ver e ouvir informações que antes só poderiam ser divulgadas pela escrita.

Além dos meios de produção tradicionais, com a era digital surge o jornalismo na web. Segundo Lopes, a nova plataforma de comunicação na internet exige dos jornalistas a abolição de antigas práticas e propõe novos desafios para a profissão e seu relacionamento com o público consumidor. Em um novo momento enfrentado por esses profissionais, conhecimentos específicos das novas ferramentas passam a ser exigidos pelo mercado das empresas de comunicação e pelas mudanças tecnológicas.

A profissão de jornalista tem como característica, ao longo da história, a passagem por frequentes transformações no âmbito de atuação e execução do ofício. Se, anteriormente, a chegada dos computadores e a aposentadoria das máquinas de escrever nas redações assustaram os jornalistas experientes dos anos 90, os profissionais de hoje tem como desafio de atuarem sob novas e avançadas tecnologias digitais, fundamentais para a construção e divulgação da notícia. (LOPES, 2019, p. 4)

Se, anteriormente, tudo era via de mão única, ou seja, poucas emissoras (os jornais, rádios e TVs), agora, no século XXI, essa estrutura foi completamente modificada (ARARIPE, EMILIÃO e ROSENBURG, 2015). Atualmente, existe uma infinidade de leitores, telespectadores, ouvintes e internautas a procura de algum conteúdo, pois o jornalismo da internet consegue circular milhares de informações em inúmeros formatos com maior rapidez e menor custo. A consequência da facilidade de divulgação de todos os tipos de conteúdo é uma crise na área de comunicação, principalmente no meio impresso. Por outro lado, surge também um novo cenário de possibilidades para investimentos das empresas de comunicação.

Por ser completamente mutável, a tendência é que o jornalismo continue evoluindo e se modificando, trazendo novos desafios àqueles que se arriscam a pô-lo em prática. Segundo Lopes, se antes o repórter era o profissional que ia para a rua apurar as informações, voltava à redação e redigia a matéria, com a entrada das tecnologias digitais esse cenário tornou-se incomum (LOPES, 2019, p.7). 


\section{Jornalismo investigativo, interesse público e ética}

De acordo com Sequeira, no Brasil o jornalismo investigativo só pode ser identificado a partir de 1975, quando o país entra no processo de abertura política, com o General Ernesto Geisel (SEQUEIRA, 2005). Antes disso, a imprensa vivia sob censura. O primeiro caso paradigmático de jornalismo investigativo foi publicado pelo jornal O Estado de S. Paulo, em 1976, com uma série de três matérias intitulada "Assim vivem os nossos superfuncionários", produzida pela equipe de reportagem coordenada pelo jornalista Ricardo Kotcho. A sequência denunciou a corrupção do setor público e mostrou os privilégios e regalias dos ministros e altos funcionários da corte instalada em Brasília e capitais federais. A matéria deu visibilidade ao que até então era invisível aos olhos da sociedade.

Há quem diga que não exista um "jornalismo investigativo", visto que todo jornalismo é obrigatoriamente investigativo, já que para se publicar uma notícia, é necessária uma prévia apuração à fundo dos fatos, independentemente do tipo de publicação. Segundo Sequeira, o termo jornalismo investigativo pode ser considerado redundante, uma vez que se pressupõe que de todo jornalismo faça parte uma investigação. Gabriel García Márquez, que exerceu as profissões de escritor e jornalista, declarou em 1966, na 52a Assembleia da Sociedade Interamericana de Imprensa, em Los Angeles, Califórnia, que "a investigação não é uma especialidade do ofício, visto que todo jornalismo tem que ser investigativo por definição." (SEQUEIRA, 2005).

No entanto, é impossível negar que existem reportagens com um apelo claramente mais investigativo do que outras. A teórica espanhola Montserrat Quesada afirma que "só no momento em que o repórter passa a usar técnicas que não fazem parte da rotina do trabalho jornalístico de atualidade, a reportagem se transforma em reportagem investigativa" (1987). Tais estratégias específicas podem ser "nada ortodoxas, às vezes" (SEQUEIRA, 2005) e abrangem desde a infiltração do profissional anonimamente no centro do acontecimento até grampos telefônicos e câmeras ocultas.

As matérias consideradas investigativas se diferem da cobertura do cotidiano, pois seriam de "maior fôlego". Dessa forma, exigem do repórter dedicação, esforço e tempo para realizar um exaustivo levantamento de informação. 
O jornalista Eugênio Bucci, um dos mais conceituados pesquisadores da imprensa em atividade no Brasil, presidente da RadioBrás, define o jornalismo investigativo como uma "modalidade especializada", que teria se desenvolvido dentro do ofício a partir de uma imposição da burocracia e de muitas máfias nacionais que colocaram sobre o direito de informação uma cortina de fumaça, capaz de barrar o direito de saber de todo cidadão. (FORTES, 2005)

Atualmente, com as transformações do mercado e a incorporação da tecnologia no exercício do jornalismo, o jornalismo investigativo vem demarcando mais seu espaço e expertise (PANACIONI, 2015, p.7). O desenvolvimento tecnológico ocorrido nas últimas décadas possibilitou a junção do uso de tecnologias, como câmeras e microfones, aos disfarces. 0 propósito alegado pelos jornalistas que o utilizam esses recursos é de revelar o que, de outra forma, continuaria supostamente escondido. Segundo Moretzsohn, o uso de câmeras e gravadores ocultos e a preparação de armadilhas para flagrar irregularidades seriam apenas uma derivação dessa prática, de acordo com as possibilidades oferecidas pelo desenvolvimento tecnológico, e estariam legitimados com o mesmo argumento (2013, p.90). Esse novo rumo que o jornalismo investigativo que desmascara e expõe "as escondidas" gera bastante discussão e controversa.

Visto tamanha controversa, torna-se relevante identificar as origens e a lógica da legitimação do repórter infiltrado com o objetivo de alertar para a necessidade do debate em torno da definição de limites para o jornalismo investigativo, especialmente importante nos tempos atuais de banalização da tecnologia digital (MORETZSOHN, 2013, p.92).

Em 2015, o Tribunal Europeu dos Direitos Humanos (TEDH) 67 considerou que o interesse público pode justificar a utilização de câmaras escondidas pelos jornalistas, numa decisão sem precedentes que condena a Suíça por ter proibido essa prática. O TEDH deu razão a quatro jornalistas condenados no seu país ao pagamento de multas por causa de uma reportagem televisiva realizada com recurso a câmara escondida em 2003 e que denunciava as más práticas comerciais no setor das seguradoras.

${ }^{6}$ AGÊNCIA LUSA. Tribunal europeu considera justificado uso de câmeras escondidas por jornalistas. Disponível em: http://www.ebc.com.br/noticias/internacional/2015/02/tribunal-europeu-considera-justificado-uso-de-camerasescondidas-por. Acesso em 10 de outubro de 2019. 
Entretanto, segundo Saback, é primeiramente essencial que se tente esclarecer as diferenças entre os conceitos de interesse público e interesse do público (2018, p.291). O pesquisador luso-brasileiro Carlos Chaparro faz distinção entre dois tipos de interesses que se misturam ou são misturados, intencionalmente ou não, pelos donos de veículos de comunicação. Segundo o autor:

O interesse do público pertence, pois, ao universo dos indivíduos, em configurações individuais ou coletivas. Está, portanto, relacionado às razões emocionais e/ou objetivas das pessoas. Razões que são a base construtora do sucesso interlocutório, sempre dependente do "outro, e que tem de ser imediato. Já o interesse público, no entendimento que a ciência política Ihe atribuiu (ver: Bobbio, Norberto; Mateucci, Nicola; e Pasquino, Gianfranco - Dicionário de Política, 5a edição, V.1, p.106, Brasília, Editora UnB, 1909), define bens imateriais, indivisíveis, que pertencem a todos, ou seja, a uma totalidade dos unidos por valoresverdade em que acreditam. Valores concretos, como a Pátria, a Família, a Igreja, ou valores abstratos, como a Justiça, a Liberdade, a Igualdade, a Dignidade, a Honra, o direito à Vida e à Felicidade. Valores motivadores e justificadores das ações humanas, inclusive as ações de narrar e analisar as coisas da Atualidade, que pertencem ao jornalismo. (CHAPARRO, 2011, p.8)

Em muitos dos casos onde há uso de tecnologia para fazer revelações, os jornalistas investigativos são questionados sobre a legalidade e a ética dos métodos utilizados, o que fomenta polêmicas, debates e dúvidas. Apesar do Código de Ética dos Jornalistas assegurar o direito ao profissional de divulgar qualquer informação que seja de interesse público ${ }^{7}$, há um conflito em relação à divulgação do rosto de qualquer pessoa envolvida na investigação. No Brasil, este fato já foi utilizado contra jornalistas em processos judiciais, e o entendimento do Superior Tribunal de Justiça em um caso específico foi de que a liberdade de imprensa não é um direito absoluto.

Em entrevista, o representante da Abraji Claudio Tognolli afirmou que o limite do jornalista é a lei. "A câmera oculta para o jornalismo e para a sociedade hoje é tão importante quanto o telescópio foi para Galileu, ou quanto o microscópio para o Leeuwenhoek. É um instrumento de buscar novos universos desde que o fundamento seja a informação de interesse público"8.

\footnotetext{
7 OMBUDSMAN. Código de Ética dos Jornalistas Brasileiros. O Povo. Disponível em: https://www20.opovo.com.br/app/ombudsman/2012/02/07/notombudsman,2779908/codigo-de-etica-dosjornalistas-brasileiros.shtml. Consultado em 2 de novembro de 2019.

${ }_{8}^{8}$ MAIA, Daniel. Perp walk: desrespeito ao direito fundamental à imagem ou exercício regular do direito de informar. Jusbrasil. Consultado em 2 de novembro de 2019
} 
Segundo Kant, "todas as ações relativas ao direito de outros homens cuja máxima não é suscetível de se tornar pública são injustas". Este é o argumento utilizado pela maior parte dos jornalistas investigativos para justificar o que fazem. O que é importante ser considerado é se o tal assunto investigado é de fato de interesse público ou se uma privacidade individual está sendo invadida sem qualquer relevância. Basicamente, é importante que o repórter tenha em mente os critérios de noticiabilidade antes de publicar algo e analisar quais interesses estão sendo afetados com a divulgação da reportagem.

Para Sartor, a noção de interesse público incide como um dos critérios básicos nas escolhas que o profissional precisa fazer, cotidianamente, ao produzir a notícia. Essas escolhas consistem em decidir quais são as ocorrências a serem noticiadas, quais são as fontes a serem ouvidas, qual o destaque ou espaço a ser atribuído para cada notícia e qual o quadro de sentidos em que devem ser emoldurados os fatos que constituem o referente do relato noticioso.

Assim, pode-se dizer que, de modo mais ou menos consciente, os jornalistas atribuem sentidos à noção de interesse público (e à ideia do que seja representar, servir ou (e à ideia do que seja representar, servir ou defender o interesse público) que lhes permitem simultaneamente identificarem-se com um grupo profissional, justificarem a importância de seu trabalho perante a sociedade e fazerem escolhas nos processos de produção noticiosa. (SARTOR, 2016, p.22)

De acordo com Christofoletti, no exercício cotidiano da cobertura dos fatos que interessam à sociedade, a conduta ética se mistura com a própria qualidade técnica de produção do trabalho. "Repórteres, redatores e editores precisam dominar equipamentos e linguagens, mas não devem se descolar de seus comprometimentos e valores" (2008, p.11).

No jornalismo investigativo, segundo Moretzsohn, questões éticas raramente são levantadas, especialmente quando se trata de pautas envolvendo um suposto combate ao crime.

É como se partíssemos do princípio de que qualquer meio é lícito para denunciar o ilícito, o que reitera alguns mitos que povoam o imaginário do público e dos próprios jornalistas sobre o papel da imprensa - o de "voz dos que não têm voz", incansável e inabalável na defesa das boas causas, sempre alerta a serviço da sociedade. Consequentemente, o estabelecimento de qualquer limite à atividade jornalística seria uma inaceitável e odiosa restrição à liberdade de informação, cuja principal vítima seria o próprio público. (2013, p.3) 
É pertinente também analisar as normas que o Código de Ética dos Jornalistas Brasileiros da Federação Nacional dos Jornalistas (FENAJ) ${ }^{9}$ dita aos jornalistas. Apesar de defender que o direito à informação e o interesse público podem justificar algumas técnicas usadas na profissão, o artigo sexto do Código, que trata do dever do jornalista, no inciso oitavo, orienta o respeito "ao direito à intimidade, à privacidade, à honra e à imagem do cidadão". Já o décimo primeiro artigo, no inciso terceiro, aponta que o jornalista não pode divulgar informações obtidas de maneira inadequada (com o uso de identidades falsas, câmeras escondidas ou microfones ocultos), "salvo em casos de incontestável interesse público e quando esgotadas todas as outras possibilidades de apuração".

É importante que os jornalistas tenham em mente que cada escolha implica em uma consequência, portanto, decisões trazem responsabilidades. Apesar de podermos considerar que a ética é algo abstrato, suas consequências podem ter repercussões concretas. Segundo Christofoletti, embora a ética não seja algo tangível, as consequências de um julgamento moral podem ser sentidas na pele e gerar graves danos. A forma que uma notícia é abordada pela mídia pode gerar grandes repercussões e, por vezes, "prejuízos de ordem material e social" (2008, p.19).

Constata-se que há grandes desafios da mídia em se manter comprometida com a ética e os valores sociais vigentes, sem deixar de noticiar e informar os cidadãos dos acontecimentos cotidianos. Nesse contexto, os profissionais de comunicação social têm o importante papel de pesar previamente suas decisões, levando em conta a ética e a proporção que tal notícia poderia ter.

\section{Fantástico e o jornalismo investigativo}

O programa Fantástico ${ }^{10}$ conta com o elenco de 10 repórteres - entre eles, Eduardo Faustini, o "repórter secreto". Faustini ${ }^{11}$, que por segurança nunca mostrou seu rosto, é um dos mais

\footnotetext{
${ }^{9}$ CÓDIGO DE ÉTICA DOS JORNALISTAS BRASILEIROS 1985/2007. 17 de novembro de 2015. Disponível em: http://fenaj.org.br/codigo-de-etica-dos-jornalistas-brasileiros-19852007/. Consultado em 10 de novembro de 2019.

10 MEMÓRIA GLOBO. "Fantástico". Disponível em http://memoriaglobo.globo.com/programas/ jornalismo/programas-jornalisticos/fantástico.htm. Consultado em 02 de maio de 2019.

${ }^{11}$ KAISER, Millos. Reportagem "O cara sem cara da Globo". Revista Trip, 2011.
} 
premiados repórteres investigativos do Brasil, responsável por matérias sobre corrupção, tráfico de drogas e venda ilegal de armas, entre outras denúncias apresentadas no programa ao longo dos anos. Proponho aqui analisar três reportagens investigativas do Fantástico, num espaço de 16 anos, que exemplificam o problema de pesquisa que apresentei previamente: "Corrupção em São Gonçalo"12, "Queima de Documentos da Ditadura"13 e "Roubo de Celular"14.

A primeira, "Corrupção em São Gonçalo", foi exibida pelo Fantástico em 21/04/2002. A reportagem tem 14 minutos e é de Eduardo Faustini, o "repórter sem rosto". Segundo o próprio Fantástico, nunca no telejornalismo havia sido registrado com tanta clareza casos de corrupção, ofertas de propina e comissões- tudo possível graças à câmera, ao microfone e à falsa identidade. A reportagem ganhou os prêmios Esso, Líbero Badaró e menção honrosa da Embratel. A segunda, "Queima de Documentos da Ditadura", foi exibida em 12/12/2004 e é de autoria dos repórteres Eduardo Faustini e Luiz Claudio Azevedo. Com duração de 19 minutos, ela denuncia a queima de documentos sigilosos da época da ditadura na Base Aérea de Salvador. A reportagem ganhou o Prêmio Qualidade Brasil e o XXII Prêmio Direitos Humanos de Jornalismo. A terceira "Roubo de Celulares", do repórter Giovani Grizotti, exibida em 21/01/2018. Esta é um pouco diferente das duas apresentadas previamente, pois não faz nenhuma grande denúncia, mas que também tem seu enredo construído com o auxílio de uma câmera escondida. A reportagem, de 14 minutos, gerou grande repercussão ${ }^{15}$ nas redes sociais e dividiu a opinião do público acerca da exposição alheia ao forjarem uma situação a partir do uso da câmera oculta.

É extensa a lista de disfarces que jornalistas podem assumir com o propósito de revelar o que, de outra forma, supostamente continuaria escondido. Faustini, desta vez, adotou o disfarce de Secretário de Governo, Planejamento e Controle Interno de São Gonçalo durante um mês para comprovar denúncias de corrupção explícita por partes de fornecedores da

12 MEMÓRIA GLOBO. "Corrupção em São Gonçalo". Disponível em: http:// memoriaglobo.globo.com/programas/jornalismo/programas-jornalisticos/fantastico/o-reporter-semrosto.htm. Acessado em 03 de maio de 2019.

13 MEMÓRIAGLOBO. "Queima de documentos da Ditadura". Disponível em http://memoriaglobo.globo.com/programas/jornalismo/telejornais-e-programas/fantastico/ fantastico-queima-dedocumentos-da-ditadura.htm. Consultado em 05 de maio de 2019.

14 FANTÁSTICO. "Com aplicativo espião instalado, siga caminho que celular roubado percorre". Disponível em: https://globoplay.globo.com/v/6437785/. Acessado em 20 de maio de 2019.

15 REDAÇÃO VEJA SÃO PAULO. "Reportagem do Fantástico sobre roubo de celulares dá o que falar". Disponível em: https://vejasp.abril.com.br/blog/pop/reportagem-fantastico-roubo-celularespolemica/. Acessado em 18 de maio de 2019. 
Prefeitura do município. Segundo Finger, não podemos esquecer que mesmo com pequenos aparatos para gravar imagens, o jornalista acaba adotando uma identidade que não a sua, o que é crime previsto no artigo 307 do Código Penal brasileiro. "Mas será que os entrevistados não têm o direito de saber com quem estão falando? Jornalista ou agente infiltrado, o limite é muito tênue" (FINGER, 2007, p.376).

Ao adotar a posição do chefe de gabinete e usar a tática do disfarce, o repórter "reforça o mito do jornalismo como instrumento de revelação da "verdade", ou seja, da possibilidade de oferecer um "retrato sem retoques" da realidade" (MORETZSOHN, 2013, p.14). O uso da câmera oculta estaria afirmando esse mito ao dar força à imagem a partir de dispositivos mecânicos, como a máquina fotográfica. A câmera oculta utilizada por Faustini, portanto, seria capaz de ver aquilo que ficaria de outro modo escondido e a imagem acaba por ganhar uma força fundamental. Segundo Brasil, "câmeras ocultas matam jornalistas e a Ética profissional e são uma prática jornalística polêmica e perigosa, tanto para a segurança dos nossos colegas quanto para a Ética da profissão" (BRASIL, 2002, p.31).

O esquema contou com a participação de George Calvert, ${ }^{16}$ o então prefeito de São Gonçalo, que permitiu que Faustini colocasse em prática o "plano". Calvert tinha completa noção do que estava acontecendo e ele próprio poderia ter encaminhado uma denúncia ao Ministério Público. Entretanto, o Fantástico decidiu que Faustini entraria em cena e que tudo seria gravado para ser exibido em rede nacional na televisão. Como ressalta Finger, o jornalista como cidadão tem o dever de tentar evitar que um crime aconteça, ou então pelo menos delatar a polícia no caso de ser testemunha de algo ilícito. Portanto, o repórter ao receber a denúncia poderia ter ido diretamente à polícia. "Se hoje a polícia e a justiça têm lá suas mazelas e efetivamente podem pouco, seria melhor dedicar-se a mostrar exatamente estas dificuldades, para que então, a mídia não precise ocupar espaços de outras instituições" (FINGER, 2007, p.76). O programa Fantástico ao colocar Faustini para assumir o gabinete da prefeitura, fazendo uma investigação especializada para a elaboração de conteúdo posteriormente entregue à polícia, adotou uma atribuição que não deveria ser sua. Porém, segundo Moretzsohn, "o impacto das cenas gravadas por câmeras ocultas é sempre muito forte. E produz um efeito de ineditismo que apaga da memória dos espectadores tudo o que já foi dito, publicado ou exibido sobre situações semelhantes" (MORETZSOHN, 2013, p.6).

${ }^{16}$ FOLHA DE S. PAULO. "Força-tarefa investiga corrupção em Prefeitura de São Gonçalo (RJ)". Jornal Folha de São Paulo, 2002. 
No Brasil, a competência para a investigação de crimes é de legitimidade das polícias Civil e Federal e do Ministério Público e é a lei quem determina como, quando e de que forma essas instituições, que fazem parte do corpo do Estado, poderão e deverão atuar. Segundo Dalmonte, o jornalismo por si só já é investigativo:

O chamado jornalismo investigativo é um termo que, a meu ver, se trata de uma redundância, pois jornalismo sem investigação é o quê? Assessoria de imprensa, talvez! O tal "jornalismo investigativo" vem a lume atribuindo a si a prerrogativa da investigação, não importando os métodos empregados: câmera e gravador escondidos, repórter com identidade falsa etc. Tudo isso em nome da investigação em profundidade. (DALMONTE, 2012, p.350)

Portanto, a conduta de Faustini na reportagem "Corrupção em São Gonçalo", assim como de qualquer outro jornalista, bem como de qualquer outro cidadão, deveria ter respeitado o princípio da estrita legalidade e qualquer excesso poderia ter sido tratado como crime. Para Dalmonte,

[...] no geral, quando se usa de artifícios ilícitos para invadir a privacidade de alguém, em nome de um suposto interesse público, são cometidas algumas transgressões, que têm como resultado imediato a atribuição de culpa a indivíduos com base nos "achados" de uma "caça às bruxas. (DALMONTE, 2012, p.352)

Esta reportagem é um típico exemplo de quando acontece uma inversão de papéis - o jornalista assume uma atribuição que não deveria ser sua e faz uma investigação "especializada" para elaborar conteúdos posteriormente entregues à polícia. É relevante considerar que nos pilares do jornalismo estão os princípios da investigação e da apuração, mas isso não dá o direito aos seus profissionais de usarem artifícios ilícitos para alcançar suas metas. O jornalismo contribui com a publicização de assuntos relevantes para a opinião pública, mas a cobiça de conseguir furos de reportagem e material exclusivo faz com que ele utilize "atos ilícitos para revelar atos ilícitos" (DALMONTE, 2012, p.358).

A mais recente das reportagens, "Roubo de Celulares"17, não faz nenhuma grande denúncia, mas também tem seu enredo construído com o auxílio de uma câmera escondida. Ela gerou

17 FANTÁSTICO. "Com o aplicativo espião instalado, siga caminho que celular roubado percorre". Disponível em: https://globoplay.globo.com/v/6437785/. Acessado em 20 de maio de 2019. 
grande repercussão ${ }^{18}$ nas redes sociais e dividiu a opinião do público acerca da exposição alheia ao forjarem uma situação a partir do uso da câmera oculta.

Com o objetivo de mostrar como os roubos ocorrem e aonde os celulares vão parar, Giovani Grizotti foi primeiramente ao Braz, um movimentado bairro de São Paulo ${ }^{19}$. O repórter estava com um celular instalado "aplicativo espião", que permitia capturar remotamente áudio e vídeo de tudo que acontecia com o celular. O celular foi colocado na parte externa de uma mochila que ele carregava nas costas, que também continha uma micro câmera oculta. Parte das filmagens da reportagem foi feita por um cinegrafista escondido num andar alto de um prédio em frente ao local. Ele também aconselhava e conversava com Giovani por meio de um ponto na ouvido do repórter. Como esta não era uma gravação explícita, podemos considerar que foi usado o recurso da câmera escondida.

Segundo Dalmonte, há uma "expectativa social de que as ações da mídia sejam sempre desenvolvidas da melhor maneira, com base nas mais elevadas concepções éticas" (DALMONTE, 2012, p.351). Porém, reportagens como essa comprovam o oposto e reforçam a ideia de que os repórteres estão dispostos a cometer excessos buscando ibope, audiência e espetacularização.

A parte mais polêmica da reportagem ocorre quando Giovani vai para Porto Alegre. Em uma rua movimentada, um homem e uma mulher agem juntos para conseguir realizar o furto: Paulo Abadie pega o celular enquanto Nara Rodrigues olha para os lados para se certificar de que ninguém estava olhando. A reportagem exibiu o caminho que o telefone foi feito pelo celular após o roubo, e exibiu diversas fotos e áudios que foram capturados pelo aplicativo espião. Podemos ver fotos de Nara mexendo no celular, que foram tiradas através da câmera frontal, e áudios de conversa entre os dois comentando sobre o roubo. Enquanto muitos elogiaram a emissora por retratar o passo a passo desse tipo de crime, a grande maioria criticou a Globo por ter forjado essa situação. Segundo Finger, "o bem comum e o interesse público podem também ser só desculpas para a nossa falta de coragem em admitir que o telejornalismo ao apostar toda sua força nas imagens, esqueceu de fazer o básico que é

18 REDAÇÃO VEJA SÃO PAULO. "Reportagem do Fantástico sobre roubo de celulares dá o que falar". Disponível em: https://vejasp.abril.com.br/blog/pop/reportagem-fantastico-roubo-celulares-polemica/. Acessado em 18 de maio de 2019.

${ }^{19}$ FANTÁSTICO. "Com aplicativo espião instalado, siga caminho que celular roubado percorre". Disponível em: https://globoplay.globo.com/v/6437785/. Acessado em 20 de maio de 2019. 
jornalismo, reportagens" (FINGER, 2007, p.77). Para a autora, a incapacidade de mediar, contar, orientar, transformar telespectadores em cidadãos melhores faz com que os repórteres fiquem presos a câmeras escondidas, armadilhas e escutas clandestinas.

Em seguida na reportagem, o repórter segue o GPS do celular e vai até o Conselho Estadual de Educação, local de trabalho de Nara. Lá, Grizzoti a aborda, liga para o celular na sua frente e a acusa de tê-lo roubado. Nara fica nervosa e constrangida enquanto o repórter a segue para todos os cantos a acusando de ter cometido um crime. Giovani também aborda, em outro momento, Paulo, o parceiro de Nara. Constrangido, primeiramente ele nega, mas depois da pressão acaba cedendo e pedindo desculpas. Nara foi afastada de seu emprego, enquanto Paulo teve uma sindicância aberta contra ele pela prefeitura. Para Moretzsohn, questões éticas raramente são levantadas, especialmente quando se trata de pautas envolvendo o combate ao crime.

É como se partíssemos do princípio de que qualquer meio é lícito para denunciar o ilícito, o que reitera alguns mitos que povoam o imaginário do público e dos próprios jornalistas sobre o papel da imprensa - o de "voz dos que não têm voz", incansável e inabalável na defesa das boas causas, sempre alerta a serviço da sociedade. (MORETZSOHN, 2013, p.2)

Esse tipo de prática não acontece só no Brasil, mas também em outras partes do mundo, como na França no programa de televisão Os infiltrados ${ }^{20}$, transmitido pela France2. Segundo Dalmonte, a proposta principal do programa, apresentado por David Pujadas, é ser o olho do cidadão, permitindo que se veja de perto tudo aquilo que a sociedade esconde (DALMONTE, 2012, p.353). O sindicato dos jornalistas franceses como "condenável", pois estaria desenvolvendo um "jornalismo de máscara." Para Jérôme Bouvier, presidente da Associação Jornalismo e Cidadania, da França,

a câmera escondida pode ser um bom álibi para fazer rápido, prevenir riscos (no caso de exposição direta). É um meio que pode ser muito prático quando inserido no contexto produtivista liberal: fazer em dois dias o que demandaria bem mais tempo sei investigássemos sem trapacear os métodos ${ }^{21}$.

\footnotetext{
20 Les Infiltrés.

21 "La caméra cachée peut être un bon alibi pour faire vite, met en garde. C'est un moyen qui peut être très pratique quand on le met à la sauce productiviste libérale: faire en deux jours ce qui demanderait bien plus de temps si on enquêtait sans tricher sur les méthodes." Disponível em: <http://www.telerama.fr/monde/de-Iinfiltration-comme-methode-journalistique,54890.php $>$.
} 
Este caso é um clássico exemplo do uso de câmera escondida no telejornalismo que fez a opinião pública debater sobre o assunto. Nas duas outras reportagens, do início dos anos 2000, as redes sociais estavam longe de existir, então só nos resta imaginar a repercussão que elas teriam tido. Na reportagem "Roubo de Celulares" podemos ver isso na prática. Um exemplo é o grupo do Facebook de Comunicação Social da PUC-Rio, aonde um post fomentou o debate acerca do modo em que a reportagem foi feita.

Na reportagem "Queima de Documentos da Ditadura", um funcionário de uma obra na Base Aérea de Salvador fez uma denuncia anônima de que papéis pertencentes ao período da ditadura militar foram retirados das cinzas do que poderia ter sido uma fogueira no local. Parte dos papéis foi enviada ao Fantástico; para comprovar que os documentos eram reais e vinham mesmo de lá, os repórteres Eduardo Faustini e André Luiz Azevedo decidiram ir até o local. A dupla conseguiu entrar no terreno da Aeronáutica com uma câmera escondida e encontraram um local com diversos documentos queimados e quase ilegíveis, onde de fato aconteceu uma fogueira. Tudo isso foi capturado pela câmera escondida. Segundo Rodriguez, "a infiltração do próprio jornalista no centro em que se quer investigar é uma técnica muito efetiva, porém altamente perigosa. Presente em países com tradição na prática deste tipo de jornalismo, é uma técnica utilizada com enorme moderação" (RODRIGUEZ, 1994, p.135).

Os repórteres encontraram partes de documentos classificados como "secretos" e "confidenciais", que coincidiam com os que foram enviados pelo informante anônimo e que teriam sido produzidos entre 1964 e 1975. De volta ao Rio, entrevistaram o perito Nelson Massini que analisou os documentos recolhidos e as imagens da suposta fogueira e confirmou o esperado: eram documentos oficiais da época que foram submetidos ao fogo e posteriormente à chuva, o que os desgastou mais ainda.

Segundo Moretzsohn, nesse tipo de prática de infiltração, os cuidados e preocupações dizem respeito estritamente à segurança dos jornalistas, sendo raros, no meio profissional, os questionamentos em relação à ética nesse tipo de procedimento (2013, p.15). Em seus Princípios Editoriais, as Organizações Globo (2011) definem, na seção II, item 2, j:

O uso de microcâmeras e gravadores escondidos, visando à publicação de reportagens, é legítimo se este for o único método capaz de registrar condutas ilícitas, criminosas ou contrárias ao interesse público. Deve ser feito com parcimônia, e em casos de gravidade. Seu uso deve ser precedido da análise, pelas chefias imediatas, dos riscos 
que correrão os jornalistas caso venham a ser descobertos. A imagem e/ou o áudio de pessoas que não estejam envolvidas diretamente no que estiver sendo denunciado devem ser protegidos. Em seus manuais de redação, os veículos devem estabelecer suas normas de uso.

A reportagem traçou um breve panorama do que foi o período militar, ressaltando o fato de que ocorriam torturas, desaparecimentos, assassinatos e repressões políticas. Faustini e Azevedo convidaram dois historiadores para analisarem os documentos que, mesmo semidestruídos e amarelados pelo fogo e pela água da chuva, ajudaram a contar um pedaço da história do Brasil naquela época. Jacob Gorender e Maria Aparecida de Aquino apontaram grande diversidade nos documentos que foram encontrados: além da Base Aérea de Salvador, também havia documentos do Ministério da Marinha, do SNI e de Pernambuco. Segundo Karam, os repórteres continuam a usar o recurso da câmera oculta sem "cerimônia nem parcimônia" nos mais diversos contextos com os mais diversos níveis de gravidade. "Dificilmente seria possível dizer que métodos tradicionais de apuração não seriam eficazes na denúncia do ilícito. Ocorre que a eficácia não está propriamente na denúncia, mas no método, que garante o espetáculo e assim, se autolegitima" (2004).

No total, foram encontrados 78 documentos ou fragmentos de documentos. Dentre eles, 10 são prontuários de pessoas consideradas subversivas; 41 são relatórios de observações de suspeitos, de relatos de ações policiais e militares e de comunicados internos; 27 são documentos de origens diversas e 7 foram classificados como "secretos" e 8 como "confidenciais". Faustini e Azevedo conversaram com diversos personagens cujo os nomes apareceram nos documentos queimados e todos, sem exceção, confirmaram a veracidade dos documentos e dos fatos neles apresentados.

Dalmonte questiona qual o limite dessa prática de jornalismo investigativo e afirma que este é um ponto crucial em seu pensamento sobre o assunto, pois, seguindo a lógica, não há limites.)

A ética seria o limite? Parece que não, uma vez que as determinações do Código Civil e da Constituição, nossa Carta Magna, são postas de lado sem o menor escrúpulo". Uma vez admitido que o jornalismo não pode se colocar acima do ordenamento jurídico, mas deve a ele estar submetido, toda estratégia contrária pode ter como resultado a quebra da confiança por parte da sociedade. Se o jornalista mentiu para conseguir informações, declarações etc, qual o limite da capacidade de mentir? (2012, p.356) 
A reportagem tomou grande repercussão nacional22: o comando da Aeronáutica determinou a abertura de um inquérito policial militar para investigar o caso e o comandante da aeronáutica afirmou que a queima era inexplicável e que queria identificar os responsáveis. Em nota, a Aeronáutica explicou que o método empregado para a destruição da documentação era incompatível com aqueles estabelecidos por suas normas regulamentares para incineração de documentos oficiais. Até a denúncia no Fantástico, a Aeronáutica negava possuir documentos referentes ao período. O ex-ministro José Dirceu, em resposta, afirmou que o governo tomou as providências de isolar o local e de apurar tudo o que aconteceu. $O$ então ministro da justiça, Márcio Thomas Bastos afirmou que documentos fazem parte da memória do Brasil e tem que ser preservados a todo custo. É possível questionar o porquê dos repórteres, ao receberem a denúncia, terem decidido ir até lá e entrarem escondidos ao invés de simplesmente terem a encaminhado ao Ministério Público. Segundo Moretzsohn, o impacto das cenas gravadas por câmeras ocultas é sempre muito forte e "produz um efeito de ineditismo que apaga da memória dos espectadores tudo o que já foi dito, publicado ou exibido sobre situações semelhante" (2012, p.17).

A câmera secreta foi essencial para que Faustini e Azevedo conseguissem provar a denúncia que uma fogueira havia sido feita na Base Aérea de Salvador e que nela havia papéis de grande importância para história brasileira. Na semana em que essa reportagem foi ao ar, em Dezembro de 2004, o governo discutia ${ }^{23}$ a abertura dos documentos oficiais referentes ao período do regime militar. A sociedade também debatia a necessidade e a urgência de que fosse aberta toda documentação secreta que pudesse dar luz a respeito da sociedade brasileira no período da ditadura. A reportagem, portanto, pode comprovar uma infração, visto que o artigo 321 do Código Penal Militar diz que é crime "extraviar livro oficial, ou qualquer documento, de que tem a guarda em razão do cargo, sonegá-lo ou inutilizado total ou parcialmente". ${ }^{24}$

\footnotetext{
22 DOURADO NEWS. "Documentos da ditadura são queimados na Bahia". Site Dourado News, 2004.

${ }^{23}$ REVISTA ÉPOCA. "Arquivos da ditadura são destruídos na Bahia". Revista Época, 2004.

${ }^{24}$ BRASIL. ARTIGO 314 CP, de 07 de dezembro de 1940. Código Penal. Diário Oficial da União, Rio de Janeiro, 31 dez. 1940.
} 


\section{Considerações finais}

Apesar de muitos dizerem que não exista um "jornalismo investigativo", visto que todo jornalismo é obrigatoriamente investigativo, já que para se publicar uma notícia, é necessária uma prévia apuração à fundo dos fatos, é impossível negar que existem reportagens com um apelo claramente mais investigativo do que outras. Comprova-se, então, a sua importância para a sociedade, visto que essas reportagens de mais fôlego e maior investimento de apuração trazem à tona, muitas vezes, assuntos que nunca chegariam ao conhecimento do povo.

O desenvolvimento tecnológico ocorrido nas últimas décadas possibilitou a junção do uso de tecnologias, como câmeras e microfones, aos disfarces. Com ele, vieram os novos desafios, e até críticas, no "novo" modo de fazer jornalismo. A controversa a respeito da ética e da legalidade do uso de tais recursos se tornou recorrente nos debates sobre tal assunto.

Nas reportagens investigativas analisadas "Corrupção em São Gonçalo" , "Queima de documentos da ditadura" e "Roubo de celulares" do programa Fantástico, da Rede Globo, pudemos comprovar a eficácia e a importância que as novas ferramentas desempenharam. Nas três, que são de épocas distintas, sem o uso da câmera oculta e da falsa identidade, as informações não teriam sido conseguidas. Elas geraram grande repercussão no público; independente da opinião acerca do uso dos recursos, é inegável a importância que tiveram para trazer à tona tais denúncias.

Por fim, por ser completamente mutável, a tendência é que o jornalismo continue evoluindo e se modificando, trazendo novos desafios àqueles que se arriscam a pô-lo em prática.

\section{Referências bibliográficas}

$A B E L$, Elie. Hutchins revisitado: trinta e cinco anos da teoria da responsabilidade social. In: SCHMUHL, Robert (Org.). As responsabilidades do jornalismo - as questões de ética no país de maior liberdade de expressão. Rio de Janeiro, Nórdica, 1987, p.51-62. ABRAMO, Cláudio. Regra do jogo: o jornalismo e a ética do marceneiro. São Paulo: Companhia das Letras, 1997, 4a reimpressão. 
ARARIPE, Evelyn; EMILIÃO, Milena; ROSENBURG, Cynthia. Comunicação na era digital: o desafio de buscar relevância em meio ao ruído. 2015.

BARROS, Antonio e DUARTE, Jorge (Orgs.). Métodos e técnicas de pesquisa em Comunicação. São Paulo: Atlas, 2009.

BASILE, Juliano. Adaptações do jornalismo em tempo de novas tecnologias. 2009. 301 f. Dissertação (Mestrado em Comunicação). Universidade de Brasília, Brasília, 2009. BRASIL, Antônio Cláudio. Telejornalismo, Internet e guerrilha tecnológica. São Paulo: Ciência Moderna, 2002.

CHRISTOFOLETTI, Rogério. A Ética no jornalismo. São Paulo: Contexto, 2008.

DALMONTE, Edson. Em nome do interesse público: o jornalismo de máscara e o uso de ações ilícitas no telejornalismo. In: Análise de telejornalismo: desafios teóricometodológicos. Salvador: EDUFBA, 2012. P. 349 a 368.

FORTES, Leandro. Jornalismo investigativo. São Paulo: Contexto, 2005.

FISK, Robert. O repórter virou um soldado. Jornal do Brasil/The Independent, 24/02/2002.

GRIFFIN, John Howard. Black like me. San Antonio: Wings Press, 2006.

INSTITUTO GUTENBERG. Crime no lide. Instituto Gutemberg, n.11, set-out./1996. KARAM, Francisco. A ética jornalística e o interesse público. São Paulo: Summus, 2004. KNEIPP, Valquíria Passos. A identificação do Jornalismo Investigativo na televisão brasileira. Intercom - Sociedade Brasileira de Estudos Interdisciplinares da Comunicação. XXXI Congresso Brasileiro de Ciếncias da Comunicação, Natal, RN. 2 a 6 de setembro de 2008.

LOPES, Daniele Vieira. O Jornalismo na era digital: impactos percebidos por repórteres e editores. XXIV Congresso de Ciências da Comunicação na Região Sudeste, DT/IJ Jornalismo,Vitória/ES, 03 a 08/06/2019

MORETZSOHN, Sylvia. O caso Tim Lopes. O mito da "mídia cidadã". In: Discursos Sediciosos - crime, direito e sociedade. Rio de Janeiro: Revan/ICC, ano 7, no 12, 2002, p. 291-316.

MORETZSOHN, Sylvia. O "repórter infiltrado" e a câmera oculta: repensando problemas éticos e epistemológicos para a prática do jornalismo. In: DALMONTE, Edson (Org.). Teoria e prática da crítica midiática. Salvador: EdUFBA, 2013, p.87-116.

PANACIONI, Gustavo. A expertise do jornalismo investigativo e o saber em empreendedorismo: uma análise a partir dos profissionais. In: III Seminário de Pesquisa em Jornalismo Investigativo, 2016, São Paulo. III Seminário de Pesquisa em Jornalismo Investigativo. São Paulo: ABRAJI, 2016. 
QUESADA, Montserrat. La investigacion periodística: El caso español. Barcelona: Editora Ariel, 1987.

RODRIGUEZ, Pepe. Periodismo de investigacion: Técnicas y estratégias. Buenos Aires: Paidos Ibérica, 1994.

SABACK, Lilian. Observatório da Imprensa (1998-2016): o fim do debate crítico sobre o jornalismo brasileiro na TV pública. Comunicação e Educação Laces e Desenlaces. 1ed. Rio de Janeiro: Atena Editora, 2018, v. 1, p.290-300.

SAVIANO, Roberto. Gomorra. A história real de um jornalista infiltrado na violenta máfia napolitana. Rio de Janeiro: Bertrand Brasil, 2008.

SEQUEIRA, Cleofe Monteiro de (2005). Jornalismo investigativo: o fato por trás da notícia. São Paulo: Summus Editorial, 2005.

SCHREIBER, Simone. A publicidade opressiva de julgamentos criminais. Rio de Janeiro: Renovar, 2008.

SEQUEIRA, Cleofe Monteiro de. Jornalismo investigativo: o fato por trás da notícia. São Paulo: Summus Editorial, 2005.

SODRÉ, Nelson Werneck. História da Imprensa no Brasil. 1966. 